\title{
Discovery of amino acid variants in the human glucose-dependent insulinotropic polypeptide (GIP) receptor: the impact on the pancreatic beta cell responses and functional expression studies in Chinese hamster fibroblast cells
}

\author{
K. Almind ${ }^{1}$, L. Ambye ${ }^{1}$, S. A. Urhammer ${ }^{1}$, T. Hansen ${ }^{1}$, S. M. Echwald ${ }^{1}$, J. J. Holst ${ }^{2}$, J. Gromada ${ }^{3}$, B. Thorens ${ }^{4}$, \\ O. Pedersen ${ }^{1}$ \\ ${ }^{1}$ Steno Diabetes Center and Hagedorn Research Institute, Copenhagen, Denmark \\ ${ }^{2}$ Department of Medical Physiology, University of Copenhagen, Denmark \\ ${ }^{3}$ Department of Islet Cell Physiology, Novo Nordisk A/S, The Symbion Science Park, Copenhagen, Denmark \\ ${ }^{4}$ Institute of Pharmacology and Toxicology, University of Lausanne, Switzerland
}

\begin{abstract}
Summary The two incretins, glucose-dependent insulinotropic polypeptide (GIP) and glucagon-like peptide-1 (GLP-1), are insulinotropic factors released from the small intestine to the blood stream in response to oral glucose ingestion. The insulinotropic effect of GLP-1 is maintained in patients with Type II (non-insulin-dependent) diabetes mellitus, whereas, for unknown reasons, the effect of GIP is diminished or lacking. We defined the exon-intron boundaries of the human GIP receptor, made a mutational analysis of the gene and identified two amino acid substitutions, A207 V and E354Q. In an association study of 227 Caucasian Type II diabetic patients and 224 matched glucose tolerant control subjects, the allelic frequency of the A207 V polymorphism was $1.1 \%$ in Type II diabetic patients and $0.7 \%$ in control subjects $(p=0.48)$, whereas the allelic frequency of the codon 354 polymorphism was $24.9 \%$ in Type II diabetic patients versus $23.2 \%$ in control subjects. Interestingly, the glucose tolerant subjects $(6 \%$ of the population) who were homozygous for the codon 354 variant had on average a $14 \%$ decrease in fasting serum C-peptide concentration $(p=0.01)$ and an $11 \%$ decrease in the same variable 30 min after an
\end{abstract}

oral glucose load $(p=0.03)$ compared with subjects with the wild-type receptor. Investigation of the function of the two GIP receptor variants in Chinese hamster fibroblasts showed, however, that the GIP-induced cAMP formation and the binding of GIP to cells expressing the variant receptors were not different from the findings in cells expressing the wildtype GIP receptor. In conclusion, amino acid variants in the GIP receptor are not associated with random Type II diabetes in patients of Danish Caucasian origin or with altered GIP binding and GIP-induced cAMP production when stably transfected in Chinese hamster fibroblasts. The finding of an association between homozygosity for the codon 354 variant and reduced fasting and post oral glucose tolerance test (OGTT) serum C-peptide concentrations, however, calls for further investigations and could suggest that GIP even in the fasting state regulates the beta-cell secretory response. [Diabetologia (1998) 41: 11941198]

Keywords Type II diabetes mellitus, genetics, GIP receptor, mutations, incretins, C-peptide response, transfections.
Received: 13 February 1998 and in final revised form: 29 May 1998

Corresponding author: K. Almind, Msc, Steno Diabetes Center, Niels Steensensvej 2, DK-2820 Gentofte, Copenhagen, Denmark

Abbreviations: GIP, Glucose-dependent insulinotropic polypeptide; GLP-1, glucagon-like peptide 1; SSCP, single strand conformation polymorphism; CHL, OGTT, oral glucose tolerance test; PCR, polymerase chain reaction.
So far, there is no clarification of the potential role of the two incretins, gastric inhibitory polypeptide/glucose-dependent insulinotropic polypeptide (GIP) and glucagon-like peptide-1 (GLP-1) in the pathogenesis of Type II (non-insulin-dependent) diabetes mellitus. Several studies have shown that there is only a minor decrease of the GLP-1 potentiated insulin response during an intravenous GLP-1 infusion in Type II diabetic patients compared with the insulinotropic response to GLP-1 in normal subjects [1]. On the other hand, a significant decrease of the insulin 
releasing response to GIP is reported in Type II diabetic patients compared with normal individuals [1]. An explanation for the diminished insulinotropic response to GIP in Type II diabetic patients, could be a reduced action of GIP on its receptor, for example caused by sequence variants in the coding region of the gene which alter the structure or expression of the receptor [2].

GIP and GLP-1 have additive insulin releasing effects and act through distinct receptors that are members of the seven transmembrane spanning G-protein coupling families. These receptors are located on the pancreatic beta cell and when stimulated by the ligands during raised plasma glucose concentrations, they elicit insulin release and enhance proinsulin gene expression. The receptors are coupled with the adenylyl cyclase pathway and interact with the glucose pathway only through cAMP-activated protein kinase [3].

The objectives of this study were 1) to determine the exon-intron organization of the human GIP receptor, 2) to test the hypothesis that genetic variability of the GIP receptor affects the pancreatic beta-cell responses in glucose tolerant subjects in the fasting state and after oral glucose or is associated with an increased prevalence of Type II diabetes and 3) to determine if stably transfected cells expressing the variant GIP receptors exhibit altered GIP-stimulated cAMP responses.

\section{Subjects, materials and methods}

Subjects. The primary mutation screening by single strand conformation polymorphism (SSCP) analysis was carried out in 61 unrelated and randomly recruited Danish Type II diabetic patients of Caucasian origin. Association studies were done on 227 unrelated Danish Caucasian Type II diabetic patients consecutively recruited from the outpatient clinic at Steno Diabetes Center and 224 age-matched, unrelated, and glucose tolerant Danish Caucasian control subjects traced in the Danish Central Population Register. All control subjects underwent a standard 75-g oral glucose tolerance test (OGTT). Informed consent was obtained from all subjects. The study was approved by the ethical committee of Copenhagen and was in accordance with the principles of the Declaration of Helsinki.

Exon-intron organization of the human GIP receptor. Polymerase chain reaction (PCR) primers were selected from the human cDNA sequence [4]. PCR amplification was performed on genomic DNA using the Expand Long Template PCR System, Expand High Fidelity PCR System and Taq polymerase (Boehringer Mannheim, Mannheim, Germany).

Single strand conformation polymorphism analysis. PCR amplification was carried out in 96-well microtitreplates on 100 ng of genomic DNA in a total volume of $25 \mu \mathrm{l}$. Primer sequences can be obtained from the authors. The PCR conditions, the electrophoresis and detection of the bands were as described previously [5].

Screening assays for identified mutations in the GIP receptor. The amino acid variant $\mathrm{A} 207 \mathrm{~V}(\mathrm{GCG} \rightarrow \mathrm{GTG})$ at exon 7 was detected by PCR amplification with primers flanking exon 7 [268 basepair (bp)] followed by digestion of the segment with HhaI (New England BioLabs Inc., Beverly, Mass., USA). The polymorphism E354Q (GAG $\rightarrow$ CAG) in exon 12 was detected by PCR amplification of a 217-bp segment and digested with BstNI.

Assays for measurement of blood variables. Plasma glucose, serum insulin and serum C-peptide were measured as reported [5]. Serum GIP was analysed with radioimmunoassay [6].

Construction of GIP receptor cDNA's. The cDNA constructs containing the GIP receptor variants were created by site directed mutagenesis with overlap extension using PCR technique. cDNA containing the full-length open reading frame of human GIP-receptor (i.e. the short form mentioned in ref. 4) inserted into the pcDNA-3 expression vector (Invitrogen, San Diego, Calif., USA) was used as a template.

cAMP assay. The cAMP production test was performed as described previously [7]. Briefly, stably transfected chinese hamster fibroblast (CHL) cells were grown for two days and then loaded with $2 \mu \mathrm{Ci}$ tritiated adenine (TRK311, Amersham, Buckinghamshire, UK). After $5 \mathrm{~h}$ at $37^{\circ} \mathrm{C}$ the cells were stimulated with different concentrations of GIP (porcine GIP, Bachem, Bubendorf Switzerland) for 9 min at $37^{\circ} \mathrm{C}$ and with $1 \mathrm{mmol} / \mathrm{l}$ isobutylmethylxanthine. The cells were lysed and the intracellular tritiated cAMP was separated on Sephadex and alumina columns as described [7].

Binding analysis. Transfected CHL cells were incubated with a fixed concentration (60000 cpm per well, $64.5 \mathrm{pmol} / \mathrm{l})$ of $\left[{ }^{125} \mathrm{I}\right] \mathrm{GIP}$ (human recombinant GIP, Amersham) for $4 \mathrm{~h}$ at $4{ }^{\circ} \mathrm{C}$ in Hank's balanced salt solution containing $20 \mathrm{mM}$ HEPES (pH 7.5) and $0.5 \%$ BSA with and without increasing concentrations of competing nonradioactive GIP.

Statistics. A Mann-Whitney test was used in Table 1 and a Student's $t$-test in Table 2. Multiple linear regression analysis was applied to find out whether there was an independent association between the homozygous carriers of the codon 354 polymorphism and serum C-peptide concentrations. The statistical analyses of the functional studies were performed with an unpaired $t$-test. The $\mathrm{IC}_{50}$ and $\mathrm{EC}_{50}$ values were calculated by nonlinear regression analyses.

\section{Results}

Characterization of the human GIP receptor gene. The human GIP receptor gene was shown to consist of 14 exons including a $5^{\prime}$ non-translated exon. The exon-intron boundaries were sequenced, in addition to approximately $100 \mathrm{bp}$ of the intronic sequences on both sites of the exons (data not shown), and were found to be identical to information submitted by Yamada et al. [8] to GenBank (Accession No. D49555D49559) after completion of our study.

Primary SSCP scanning of the GIP receptor. Genomic DNA from 61 Type II diabetic patients was included in the primary SSCP scanning of the 14 exons including approximately $50 \mathrm{bp}$ of the intronic sequence both upstream and downstream of the exons. The 
Table 1. Clinical and biochemical characteristics of 224 glucose tolerant control subjects carrying the wild-type, the heterozygous or the homozygous codon 354 polymorphism in the GIP receptor

\begin{tabular}{|c|c|c|c|c|}
\hline & $\begin{array}{l}\text { Wild-type } \\
\text { codon } 354 \\
\text { mean } \pm \text { SD }\end{array}$ & $\begin{array}{l}\text { Heterozygous } \\
\text { codon } 354 \\
\text { mean } \pm \text { SD }\end{array}$ & $\begin{array}{l}\text { Homozygous } \\
\text { codon } 354 \\
\text { mean } \pm \text { SD }\end{array}$ & $p^{1}$ \\
\hline$n$ and sex (female/male) & $134(67 / 67)$ & $76(38 / 38)$ & $14(7 / 7)$ & \\
\hline Age (years) & $51.5 \pm 14.1$ & $52.4 \pm 13.3$ & $52.2 \pm 14.1$ & 0.92 \\
\hline Body-mass index $\left(\mathrm{kg} / \mathrm{m}^{2}\right)$ & $25.7 \pm 4.1$ & $24.6 \pm 3.3$ & $24.2 \pm 3.4$ & 0.10 \\
\hline Waist-hip ratio & $0.90 \pm 0.1$ & $0.87 \pm 0.1$ & $0.88 \pm 0.1$ & 0.97 \\
\hline F-p-glucose $(\mathrm{mmol} / \mathrm{l})$ & $5.1 \pm 0.6$ & $5.1 \pm 0.5$ & $5.2 \pm 0.4$ & 0.43 \\
\hline F-s-insulin $(\mathrm{pmol} / \mathrm{l})$ & $41 \pm 20$ & $40 \pm 20$ & $41 \pm 31$ & 0.39 \\
\hline F-s-C-peptide (pmol/l) & $557 \pm 154$ & $557 \pm 145$ & $477 \pm 179$ & 0.01 \\
\hline AUC insulin $(\mathrm{pmol} / \mathrm{l})$ & $7925 \pm 3840$ & $7666 \pm 4263$ & $7562 \pm 7191$ & 0.14 \\
\hline AUC C-peptide (pmol/l) & $50112 \pm 13775$ & $50198 \pm 16629$ & $44378 \pm 18924$ & 0.03 \\
\hline AUC glucose $(\mathrm{mmol} / \mathrm{l})$ & $230 \pm 43$ & $233 \pm 43$ & $238 \pm 30$ & 0.33 \\
\hline
\end{tabular}

${ }^{1}$ Comparing subjects homozygous for the codon 354 polymorphism to wild-type carriers. AUC is area under the curve after an oral glucose tolerance test (0-30 $\mathrm{min})$.

$\mathrm{F}$ denotes fasting, $\mathrm{s}$ denotes serum and $\mathrm{p}$ denotes plasma.

Table 2. GIP concentrations in serum from 14 glucose tolerant homozygous (Ho) carriers of the codon E354Q variant of the GIP receptor and from 14 matched wild-type (Wt) carriers, measured before and during an OGTT

\begin{tabular}{|c|c|c|c|c|c|}
\hline & \multicolumn{5}{|c|}{ Serum GIP concentration $(\mathrm{pmol} / \mathrm{l})$} \\
\hline & $0 \mathrm{~min}$ & $30 \mathrm{~min}$ & $60 \mathrm{~min}$ & $120 \mathrm{~min}$ & $180 \mathrm{~min}$ \\
\hline $\mathrm{Wt}$ & $5.0 \pm 3.0$ & $44.9 \pm 20.8$ & $56.0 \pm 23.8$ & $47.2 \pm 23.3$ & $18.0 \pm 12.4$ \\
\hline Ho & $6.7 \pm 4.9$ & $51.5 \pm 27.8$ & $54.5 \pm 21.3$ & $47.3 \pm 30.6$ & $23.8 \pm 17.2$ \\
\hline$p$-value ${ }^{1}$ & 0.29 & 0.50 & 0.87 & 0.99 & 0.33 \\
\hline
\end{tabular}

${ }^{1}$ Comparing subjects homozygous for codon 354 polymorphism with wild-type carriers.

Data are mean \pm SD

subsequent sequencing showed a heterozygous GCG to GTG substitution in exon 7 at codon 207 changing an alanine to a valine (A207V) and a common polymorphism in exon 12 at codon 354 in which GAG was changed to CAG causing a substitution of glutamic acid by glutamine (E354Q).

Association studies of missense amino acid variants in the GIP receptor. The polymorphism at codon 354 was frequent in both control subjects and in the Type II diabetic patients, with allelic frequencies of $23.2 \%$ (95\% confidence interval 19.3-27.1) and $24.9 \%$ (20.9-28.9), respectively. The allelic frequencies of the alanine to valine amino acid substitution of codon 207 were $0.7 \%(0-1.5)$ for control subjects and $1.1 \%$ $(0.1-2.1)$ for Type II diabetic patients $(p=0.48)$. The observed genotype frequencies were in Hardy-Weinberg equilibrium.

Characteristics of glucose tolerant subjects carrying amino acid variants in the GIP receptor. The clinical characteristics of control subjects carrying the codon 354 polymorphism are presented in Table 1 . The serum insulin and plasma glucose concentrations at fasting and during the initial $30 \mathrm{~min}$ of the OGTT are comparable for all subjects. The subjects homozygous for the codon 354 polymorphism, however, had a $14 \%$ decrease in fasting serum C-peptide concentration $(p=0.01)$ as compared with subjects carrying the wild-type GIP receptor. The serum C-peptide concentration was still lower $[1670 \pm 459$ vs $1479 \pm 630($ mean \pm SD $), p=0.034)] 30$ min after the glucose load. When adjusting for sex, BMI and age in a multivariate analysis, the fasting serum C-peptide concentration remained lower $(p=0.02)$. The 3 subjects carrying the A207V amino acid substitution were almost indistinguishable from the wild-type carriers (results not shown). GIP concentrations were measured in serum in the fasting state and at 30,60, 120 and $180 \mathrm{~min}$ after an oral glucose load from the 14 subjects with the homozygous codon 354 polymorphism and in 14 wild-type carriers matched by sex, BMI and age (Table 2). The serum GIP concentrations were on average increased by $25 \%$ during fasting in homozygous subjects $(p=0.30)$ and it increased considerably in both groups after glucose ingestion.

GIP stimulated cAMP production. Two independent clones expressing the A207V variant GIP receptor, as well as two independent clones expressing the E354Q variant and the wild-type GIP receptors, respectively, were selected for the functional studies on the basis of similar cAMP productions to a maximum GIP stimmulation. The clinical studies of glucose tolerant subjects may suggest that GIP in the fasting state could have a diminished activating effect on GIP receptors containing the polymorphism 

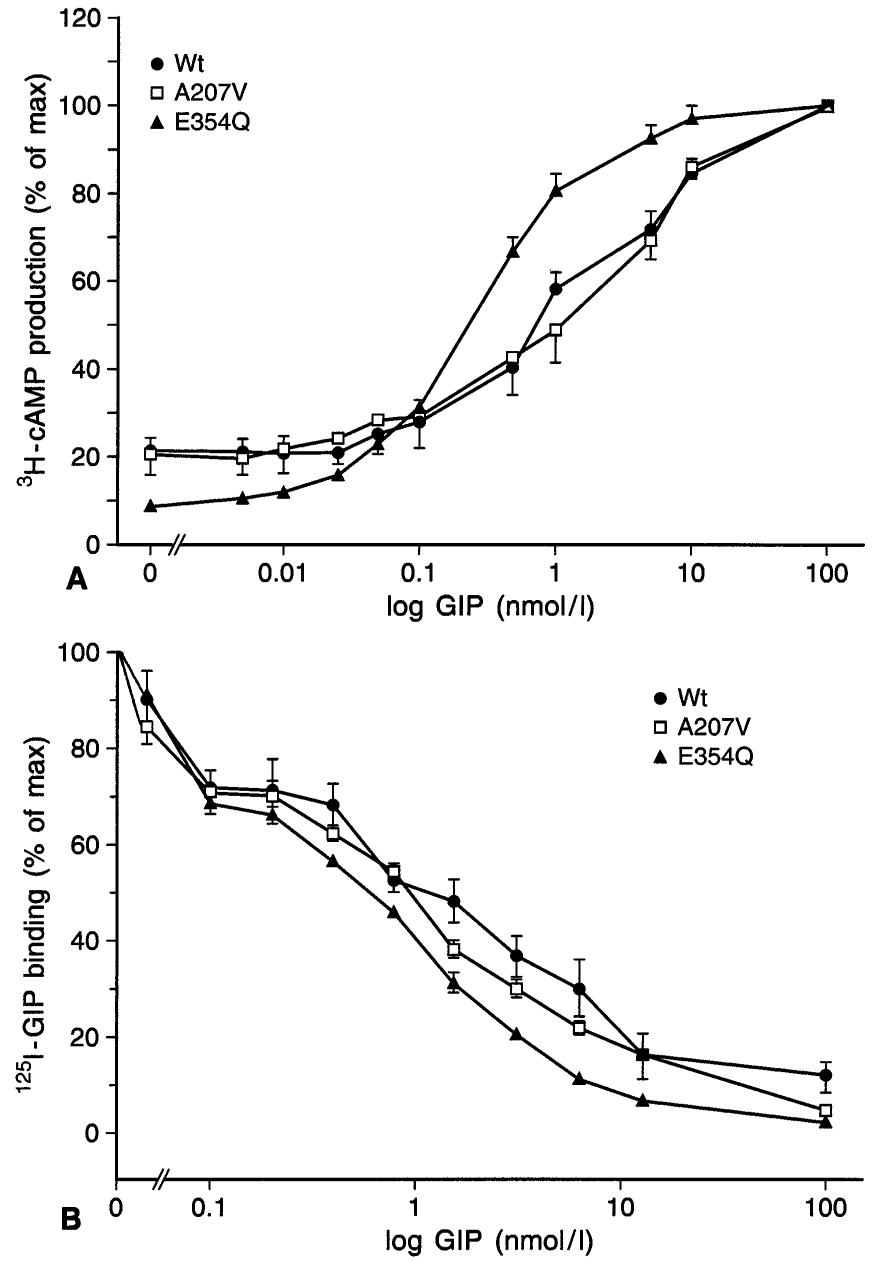

Fig. 1 Dose-dependent analyses of GIP-induced cAMP production (A) and displacement of radioactive GIP binding to its receptor by non-radioactive GIP (B) in stably transfected Chinese hamster fibroblasts expressing wild-type GIP receptor, A207VGIP receptor and E354QGIP receptor, respectively. (A) The experiment was performed 2-3 times and each curve represents the average of the two independent cell lines. Results are expressed as per cent of maximum response. The $\mathrm{EC}_{50}$ values are $3.63 \mathrm{nmol} / \mathrm{l}$ (wild-type receptor), $1.18 \mathrm{nmol} / \mathrm{l}$ $(\mathrm{A} 207 \mathrm{~V})$ and $0.25 \mathrm{nmol} / \mathrm{l}(\mathrm{E} 354 \mathrm{Q})$ and data are mean $\pm \mathrm{SEM}$. (B) Each experiment was performed in triplicate and each data point is expressed as per cent of maximum counts per minute and represents the average of the two independent cell lines. The $\mathrm{IC}_{50}$ values are $1.14 \mathrm{nmol} / \mathrm{l}$ (wild-type receptor), $0.84 \mathrm{nmol} / \mathrm{l}(\mathrm{A} 207 \mathrm{~V})$ and $0.53 \mathrm{nmol} / \mathrm{l}(\mathrm{E} 354 \mathrm{Q})$ and data are mean \pm SEM

at codon 354. To show this possibility the CHL cells were stimulated with GIP at concentrations ranging from $0-100 \mathrm{nmol} / \mathrm{l}$, including several points at low GIP concentrations, and the response to GIP was assayed by measuring the cAMP production (Fig.1A). Cells expressing the receptor mutated at codon 354 had at the basal state and at very low GIP concentrations (lower than $0.01 \mathrm{nmol} / \mathrm{l}$ ) an approximately $11 \%$ lower GIP stimulated production of cAMP compared with CHL cells expressing either wildtype GIP receptors or the A207V variant (not signif- icant). A raise of the GIP concentrations resulted in a more pronounced cAMP production in cells expressing the codon 354 polymorphism and consequently resulted in a lower (not significant) median effect concentration $\left(\mathrm{EC}_{50}\right)$ value $(0.25 \mathrm{nmol} / \mathrm{l})$ than in cells expressing wild-type or the codon 207 variant with $\mathrm{EC}_{50}$ values of $3.63 \mathrm{nmol} / \mathrm{l}$ and $1.18 \mathrm{nmol} / \mathrm{l}$, respectively.

Binding of GIP to the GIP receptor. The binding of GIP to its receptor was studied to show any potential differences in the affinity of GIP to the various forms of the receptor. The displacement of iodinated GIP binding to the GIP receptor by non-radioactive GIP $(0-1 \mu \mathrm{mol} / \mathrm{l})$ at a fixed concentration of radioactive trace GIP is shown in Figure 1B. The displacement of ${ }^{125} \mathrm{I}$-GIP from GIP receptors containing the codon 207 or codon 354 amino acid substitutions occurred at almost the same GIP concentrations as the displacement from the wild-type receptor. The median inhibitory concentration $\left(\mathrm{IC}_{50}\right)$ values measured from the cells expressing either wild-type, A207V and E354Q GIP receptors were consequently also very similar $(1.14 \mathrm{nmol} / 1,0.84 \mathrm{nmol} / 1$ and $0.53 \mathrm{nmol} /$ 1 , respectively) (not significant).

\section{Discussion}

The codon 354 amino acid polymorphism of the GIP receptor is carried by approximately $40 \%$ of the examined Danish Caucasian population sample. Interestingly, the glucose tolerant subjects carrying the amino acid substitution of codon 354 on both alleles (6\% of the population) had significantly lower fasting and 30 min post-OGTT serum C-peptide concentrations, when compared with the wild-type carriers, whereas the serum insulin and plasma glucose concentrations were similar. The mechanisms behind the normal fasting serum insulin concentration in the face of an adaptive fasting serum C-peptide concentration are not known, but the findings could be explained by a compensatory decrease of the hepatic degradation of insulin, secondary to a lower insulin secretion. If the present data can be replicated they suggest that GIP might have a role in controlling the maintenance of euglycaemia in the fasting as well as in the postprandial state.

After the discovery of reduced fasting serum Cpeptide concentrations in subjects homozygous for the codon 354 polymorphism, the serum GIP concentrations in the same subjects were measured to see if the amino acid substitution was associated with a compensatory increase in circulating GIP concentrations, which potentially could be related to a less effective transmission of the signal elicited by the ligand binding. Although the fasting serum GIP concentrations on average were $25 \%$ higher in homozy- 
gous carriers of the codon 354 variant, this difference did not attain statistical significance.

The association study showed that the codon 354 variant in itself does not confer an increased risk of Type II diabetes. Kubota et al. [9] reported their findings from mutational screening of the GIP receptor gene in the Japanese population. The detected allelic frequencies of the E354Q variant were in accordance with our results in Caucasians. The glutamic acid at codon 354 is located in the middle of the sixth membrane-spanning domain and it is conserved among human, rat and hamster GIP receptors. A transfection study in Chinese hamster ovary cells has been reported previously [9] which showed no difference in the unstimulated cAMP concentrations between Chinese hamster ovary cells expressing the normal GIP receptor and the E354Q GIP receptor and furthermore, no differences were seen in maximum or submaximum responses in cAMP formation to various concentrations of GIP. In a transfection study of the CHL fibroblasts we tried to go a little further and examined the GIP-stimulated cAMP production at GIP concentrations corresponding to in vivo fasting concentrations and, moreover, we studied GIP binding to its receptor. The basal cAMP production was lower in cells expressing the codon 354 variant compared with wild-type. Nevertheless, the course during the entire dose-response was not different among the cell lines. Furthermore, the binding experiment showed no difference in affinity of the GIP receptor to its ligand in cells expressing wild-type or the E354Q variant. Obviously, the examination of the pharmacology of the mutated receptors in fibroblast cell lines is not a sensitive evaluation of the receptor function since essential elements in the signalling pathways for insulin synthesis and secretion are lacking in these non-pancreatic cells. For instance, GIP stimulates insulin secretion from beta cells through the cAMP/PKA signalling pathway by interacting with the secretory machinery at a late step exerted distal to an elevation in intracellular free calcium concentrations [10]. Unfortunately, it was not possible to explore this pathway in the cells expressing the variant receptors because of the lack of a GIPstimulated calcium response in the CHL fibroblasts (Almind $\mathrm{K}$ and Gromada J, unpublished observations).
Acknowledgements. This study was supported by grants from the University of Copenhagen, the Danish Medical Research Council, the Danish Diabetes Association, the Velux Foundation and EEC (BMH4-CT-950662). The authors wish to thank Wanda Dolci, Annemette Forman, Bente Mottlau, Lene Aabo, Sandra Urioste, Susanne Kjellberg and Jane Broenum for technical assistance and Dr Steen Lovmand at DNA Technology, Aarhus, Denmark for his contributions to the studies of the exon-intron boundaries of the human GIP receptor.

\section{References}

1. Nauck MA, Heimesaat MM, Ørskov C, Holst JJ, Ebert R, Creutzfeldt W (1993) Preserved incretin activity of glucagon-like peptide 1 [7-36 amide] but not of synthetic human gastric inhibitory polypeptide in patients with type-2 diabetes mellitus. J Clin Invest 91: 301-307

2. Holst JJ, Gromada J, Nauck MA (1997) The pathogenesis of NIDDM involves a defective expression of the GIP receptor. Diabetologia 40: 984-986

3. Thorens B (1995) Glucagon-like peptide-1 and control of insulin secretion. Diabetes Metab 21: 311-318

4. Gremlich S, Porret A, Hani EH et al. (1995) Cloning, functional expression, and chromosomal localization of the human pancreatic islet glucose-dependent insulinotropic polypeptide receptor. Diabetes 44: 1201-1208

5. Almind K, Bjørbæk C, Vestergaard H, Hansen T, Echwald S, Pedersen O (1993) Amino acid polymorphisms of insulin receptor substrate-1 in non-insulin-dependent diabetes mellitus. Lancet 342: 828-832

6. Krarup T, Madsbad S, Moody AJ et al. (1983) Diminished immunoreactive gastric inhibitory polypeptide (GIP) response to a meal in newly diagnosed type I (insulin dependent) diabetics. J Clin Endocrinol Metab 56: 1306-1312

7. Widmann C, Bürki E, Dolci W, Thorens B (1994) Signal transduction by the cloned glucagon-like peptide-1 receptor: comparison with signaling by the endogenous receptors of $\beta$ cell lines. Mol Pharmocol 45: 1029-1035

8. Yamada Y, Hayami T, Nakamura K et al. (1995) Human gastric inhibitory polypeptide receptor: cloning of the gene (GIPR) and cDNA. Genomics 29: 773-776

9. Kubota A, Yamada Y, Hayami Tet al. (1996) Identification of two missense mutations in the GIP receptor gene: a functional study and association analysis with NIDDM. Diabetes 45: 1701-1705

10. Ding W, Gromada J (1997) Protein kinase A-dependent stimulation of exocytosis in mouse pancreatic $\beta$-cells by glucose-dependent insulinotropic polypeptide. Diabetes 46: 615-621 